\title{
An investigation of preschool classroom behavioral adjustment problems and social-emotional school readiness competencies
}

\author{
John W. Fantuzzo ${ }^{\mathrm{a}, *}$, Rebecca Bulotsky-Shearer ${ }^{\mathrm{b}}$, \\ Rachel A. Fusco ${ }^{a}$, Christine McWayne ${ }^{c}$ \\ a University of Pennsylvania, Graduate School of Education, 3700 Walnut Street, Philadelphia, PA 19104-6216, USA \\ b School District of Philadelphia, PA, USA \\ ${ }^{\mathrm{c}}$ New York University, Steinhardt School of Education, NY, USA
}

\begin{abstract}
The study examined the unique relationship between multiple dimensions of classroom behavioral adjustment problems and salient social-emotional competencies for urban Head Start children. These relationships were investigated using a hierarchical model that controlled for the variance in social-emotional outcomes attributed to age, gender, and verbal ability. Classroom behavioral adjustment problems were assessed early in the year by the Adjustment Scales for Preschool Intervention (ASPI) across multiple, routine preschool classroom situations. Outcomes assessed at the end of the year included emotion regulation, peer play in the home and neighborhood context, and approaches to learning. Socially negative behavior in the classroom predicted emotional lability, maladaptive learning behaviors, and disruptive social play in the home at the end of the year. Withdrawn behavior uniquely predicted lower affective engagement in the classroom and disconnection from peers in the home context. Findings provide predictive validity for the ASPI. Implications for policy, practice and future research are discussed.
\end{abstract} (C) 2005 Elsevier Inc. All rights reserved.

Keywords: Social-emotional; Children; Behavior; Head start; Classroom behavior; School readiness

Recently, much national attention has been paid to the contribution of social and emotional readiness to children's school success (National Education Goals Panel, 1997; U.S. Department of Health and Human Services (USDHHS), 2001). Research documents the negative influence of social, regulatory, and emotional problems on children's early school experiences (Knitzer, 2003; Raver, 2002; Shonkoff \& Phillips, 2000). Preschool children who exhibit challenges in these areas are more likely to experience

\footnotetext{
* Corresponding author. Tel.: +1 2158984790.

E-mail address: johnf@gse.upenn.edu (J.W. Fantuzzo).
} 
difficulties within the classroom that affect their ability to develop normal peer relationships and to behave in ways conducive to learning (Vaughn et al., 1992). As a consequence, these children are less likely to be socially and academically prepared for school (Huffman, Mehlinger, \& Kerivan, 2000).

Unfortunately, epidemiological studies indicate that as many as 10-15\% of preschool children exhibit moderate to clinically significant emotional and behavioral difficulties (Lavigne et al., 1996; Qi \& Kaiser, 2003). At highest risk for these problems, are low-income children who are disproportionately exposed to risks to their health and well being (Brooks-Gunn \& Duncan, 1997; McLoyd, 1998). For these children, the prevalence of emotional and behavioral problems is even higher (Lavigne et al., 1996; Sinclair, Del'Homme, \& Gonzalez, 1993). Further, children living in disadvantaged urban areas are at heightened risk for school adjustment difficulties. They are less likely to enter school systems with adequate resources to meet their educational and social-emotional needs (U.S. Department of Education, 1996).

The occurrence of classroom behavioral adjustment problems in low-income, preschool children is best understood from a developmental psychopathology perspective (Cicchetti \& Sroufe, 2000). Two principles exemplify this model: (a) the importance of understanding the influence of early patterns of adaptation on later development and (b) the recognition that child functioning is influenced by important proximal contexts such as school and home (Cicchetti \& Sroufe, 2000). According to a developmental psychopathology perspective, children's developmental trajectories are influenced by early patterns of adjustment. All children have the potential to set out on a positive developmental course; however, early difficulties place children at risk for future problems. In addition, classroom behavioral adjustment problems are viewed as arising in dynamic transaction between children and the demands of primary contexts (Cicchetti \& Sroufe, 2000). Therefore, it is critically important to study young children's behavior problems within proximal contexts, such as the preschool classroom and home.

In line with this developmental perspective, a growing body of research documents the negative influence of early behavior problems on children's academic and social outcomes. A review of the literature provides evidence from a number of longitudinal studies that behavior problems identified in the preschool years are often stable and lead to additional problems within the school classroom (Qi \& Kaiser, 2003). Other research indicates that children with early behavioral problems experience difficulties interacting with teachers, parents and peers, and engaging in classroom learning activities (Harden et al., 2000; Olson \& Hoza, 1993).

While current studies highlight the negative influence of preschool emotional and behavioral problems, these study findings are limited for low-income preschool children. First, behavior problems are frequently not studied or assessed within naturalistic settings such as the preschool classroom. Second, available tools used to assess classroom behavioral adjustment problems often lack reliability or validity for lowincome preschool populations (Lopez, Tarullo, Forness, \& Boyce, 2000). Commonly used methods, such as psychiatric checklists of mental disorders, have come under criticism for use with diverse, low-income populations because of their illness orientation and lack of contextual sensitivity (Drotar, Stein, \& Perrin, 1995; Fantuzzo \& Mohr, 2000; Sherrod, 1999). Empirical studies indicate that early childhood educators, particularly those serving low-income children, underreport classroom behavioral adjustment problems when using these types of measures to avoid stigmatizing children with labels that are not associated with needed classroom-based services (Mallory \& Kearns, 1998).

In response to the need for reliable and valid assessment of problems within the classroom, McDermott (1993) developed an alternative approach to assessing children's classroom behavioral adjustment problems. Recently, this method was used to develop the Adjustment Scales for Preschool Intervention (ASPI) a measure to assess low-income children being served in early childhood programs (Lutz, Fantuzzo, \& 
McDermott, 2002). The ASPI was created in partnership with early childhood professionals, including teachers and disability coordinators. These professionals selected both routine classroom situations and adaptive and maladaptive behaviors associated with these situations. The scale describes behavior that is readily observable over a 1- or 2-month period within routine classroom situations, thus reducing the need for teachers to make inferences regarding children's internal mediating psychological processes (such as thoughts or feelings, e.g., "child seems sad"). Studies with urban, low-income preschool children have established the ASPI as a valid and reliable, multidimensional measure of classroom behavioral adjustment adjustment (Bulotsky-Shearer \& Fantuzzo, 2004; Lutz et al., 2002). The five dimensions of preschool adjustment include: Aggressive, Oppositional, Inattentive/Hyperactive, Withdrawn/Low Energy and Socially Reticent problems (Lutz et al., 2002).

To date, there has been only one study that has examined the predictive relationship between ASPI dimensions identified early in children's Head Start experience and selected social competency outcomes (Fantuzzo, Bulotsky, McDermott, Mosca, \& Lutz, 2003). This study used teacher reports of children's peer play to measure children's end-of-the-year outcomes. Findings indicated that early socially disruptive classroom behavior problems (e.g., aggressive and oppositional problems) were associated with socially disruptive classroom peer play at the end of the year. Aggressive problem behaviors were the strongest predictor of disruptive peer play outcomes. Additionally, early socially disconnected and withdrawn behavior problems within the classroom context predicted disengagement in play. Both socially reticent and withdrawn/low energy problem behaviors were associated with disconnected peer play and negatively related to prosocial, interactive peer play outcomes (Fantuzzo \& Bulotsky, 2003).

The present study was designed to extend this initial ASPI research in two important ways. First, given the recent attention to the critical role of emotional regulation in classroom behavioral adjustment (Shonkoff \& Phillips, 2000), we sought to take a closer look at the relationship between behavioral problems and a multidimensional measure of emotional regulation. Research suggests that internal regulatory skills such as awareness and recognition of one's own emotions and effective regulation of emotional expression within social interactions are critical for positive peer interactions and successful engagement within the classroom learning environment (Denham, 1998; Denham, Salisch, Olthof, Kochanoff, \& Caverly, 2002; Denham et al., 2003; Eisenberg et al., 2001; Shields et al., 2001).

Second, we wanted to examine the relationship between classroom behavioral adjustment and additional peer and classroom social outcomes. Studies suggest that the ability to interact effectively with peers is a key social competency for preschool children (Coolahan, Fantuzzo, Mendez, \& McDermott, 2000; Fantuzzo \& Hampton, 2000; Rubin \& Coplan, 1998). The research suggests that children exhibiting classroom behavioral problems are likely to experience peer difficulties as well (Eisenberg \& Fabes, 1992; Fantuzzo \& McWayne, 2002). For the present study, we sought to extend investigation of peer play interaction into the home and neighborhood context. In addition, it was important to examine a second competency, foundational approaches to learning. This is defined as children's ability to engage in learning activities with others in the classroom, including "flexibility, reflectivity, strategic problemsolving, vigilance, persistence, response to novelty, and error, as well as manifestations of effectiveness motivation and attitudes towards learning" (NEGP, 1997). Research conducted in Head Start suggests that approaches to learning are critical skills for preschool readiness (Coolahan et al., 2000; Fantuzzo, Perry, \& McDermott, 2004; McDermott, Leigh, \& Perry, 2002).

The primary goal of the present study was to investigate the unique contribution of early emotional and behavioral problems to this set of social competencies: (a) emotional regulation, (b) peer play in the home context, and (c) foundational approaches to learning in the school context. To examine unique 
relationships, this study used a complex hierarchical model to take into account age, gender, and verbal ability since studies have revealed a relationship between early classroom behavioral problems and these variables (Coolahan et al., 2000; Fantuzzo et al., 2001; Harden et al., 2000; Kaiser, Cai, Hancock, \& Foster, 2002; Qi \& Kaiser, 2003). We hypothesized that early socially negative behavior problems would predict greater emotional lability, maladaptive learning behaviors, and disruptive social play in the home environment, controlling for the influence of children's age, gender, and verbal ability. In addition, withdrawn behavior problems would be uniquely associated with lower affective engagement (emotional regulation) in the classroom and disconnection from play with peers in the home context.

\section{Method}

\subsection{Participants}

The participants in this study were a representative sample drawn from a large, urban Head Start program in the Northeast. Children were recruited from 12 classrooms representing the program's six geographical clusters. The 210 children ranged in age from 42 to 76 months $(M=58$, S.D. $=7.3)$. Gender was evenly distributed: $52 \%$ were male and $48 \%$ were female. The majority of the children were AfricanAmerican (92\%), with the remaining 2\% Caucasian, 2\% Asian, 1\% Hispanic, and 3\% other. Family income in the program matched national proportions for urban Head Start programs, with annual income for $94 \%$ of the families below US\$12,000.

\subsection{Fall measures}

\subsubsection{Classroom behavioral adjustment adjustment}

Preschool classroom behavioral adjustment was measured by the Adjustment Scales for Preschool Intervention (ASPI; Lutz et al., 2002), a multidimensional instrument based on teacher observations of adaptive and maladaptive behavior in the preschool classroom. The ASPI was standardized on a sample of urban Head Start children and validated for use with this population (for more extensive description of standardization, see Lutz et al., 2002). The ASPI contains 144 observable preschool classroom behaviors (122 items reflect problem behaviors, 22 items reflect positive behaviors). These items are each framed by 22 routine classroom situations such as, interactions with teacher, peers, and involvement in structured and unstructured classroom activities, games, and play. ASPI content focuses on teacher observed behavior over the preceding 2 months. Teachers check if they have observed the behavior (yes or no indication).

Construct validity studies of the ASPI with urban, low-income preschool populations have revealed five robust and reliable phenotypic dimensions: Aggressive, Oppositional, Inattentive/Hyperactive, Withdrawn/Low Energy, and Socially Reticent. Each of the five dimensions demonstrated adequate internal consistency, with Cronbach's alpha coefficients of .92, .78, .79, .85, and .79, respectively (Lutz et al., 2002). ASPI dimensions showed significant test-retest stability (McDermott, Bulotsky-Shearer, \& Fantuzzo, 2003). Convergent and divergent validity of the five ASPI dimensions has been established with constructs of interactive peer play, behavior problems, temperament, emotion regulation, and direct observations of classroom behavior problems (Bulotsky-Shearer \& Fantuzzo, 2004; Lutz et al., 2002). 


\subsection{Spring measures}

\subsubsection{Emotion regulation}

The Emotion Regulation Checklist (ERC; Shields \& Cicchetti, 1995; Shields \& Cicchetti, 1997) is a 24-item scale completed by teachers. It measures processes central to emotionality and regulation, such as affective lability, intensity, flexibility, and situational appropriateness of emotional expression. Children's classroom behavior is rated on a four-point Likert scale to assess the degree to which the item characteristic fits the child. Factor analyses on a sample of 513 maltreated and impoverished children (6-12 years old) revealed two reliable, underlying dimensions, emotion regulation, and lability/negativity. These two factors were replicated in a sample of Head Start children and demonstrated adequate internal consistency, Cronbach's alpha $=.81$ and .90 , respectively (Shields et al., 2001). The Emotion regulation dimension describes appropriate affective displays, empathy, and emotional self-awareness; sample items include "Is empathic toward others," and "Can say when she/he is feeling sad, angry or mad, fearful or afraid" (Shields \& Cicchetti, 1995, 1997). The lability/negativity subscale reflects behavior including mood swings, angry reactivity, and intensity of positive and negative emotions, for example, "exhibits wide mood swings."

\subsubsection{Interactive peer play}

The parent version of the Penn Interactive Peer Play Scale (PIPPS-P; Fantuzzo, Mendez, \& Tighe, 1998) is a 32-item rating scale used to measure common play behaviors that facilitate or interfere with prosocial peer interactions in the home and neighborhood context. The PIPPS-P was developed in collaboration with Head Start parents and teachers specifically for use with low-income, urban Head Start children. Reliability and validity studies of the PIPPS-P revealed three reliable dimensions: Play Disconnection, Play Disruption, and Play Interaction (Cronbach's alpha $=.74, .81$, and .84 , respectively). The parent version of the PIPPS was validated by the teacher version of the PIPPS with high factorial congruence between the three PIPPS parent and teacher constructs (Fantuzzo et al., 1998). In addition, Fantuzzo and McWayne (2002) demonstrated a strong association between peer play in the home context and children's classroom behaviors (school-based peer play, approaches to learning, self-regulation, and behavior problems).

\subsubsection{Approaches to learning}

The Preschool Learning Behaviors Scale (PLBS; (McDermott, Green, Francis, \& Stott, 1996; McDermott et al., 2002) was used to assess children's approaches to learning. The PLBS contains 29 items reflecting child behavior that teachers rate on a three-point scale ("most often applies", "sometimes applies," and "does not apply"). Construct validity studies yielded three reliable learning behavior dimensions: Competence Motivation, Attention Persistence, and Attitude Toward Learning ( $r=.85, .83$, and .75, respectively) (McDermott et al., 1996; McDermott et al., 2002). Items on the Competence Motivation scale reflect children's willingness or reluctance to take on tasks, and their determination to successfully complete activities. The Attention Persistence dimension contains items assessing the degree to which children pay attention and are able to follow tasks through to completion. Items on the Attitude Toward Learning scale focus on concepts such as children's willingness to be helped, desire to please the teacher, and propensity to express hostility when frustrated. The PLBS has been validated for use with a Head Start population (Fantuzzo et al., 2004). 


\subsubsection{Verbal ability}

The Verbal Ability Cluster score from the Differential Abilities Scale (DAS; Elliot, 1990) was used to measure verbal ability. The DAS is an individually administered test of general intellectual ability that provides one overall general intelligence quotient as well as three indexes of differentiated ability (Verbal, Nonverbal Reasoning, and Spatial). For preschool-aged children, the Verbal Ability Cluster is generated by administration of two subscales: Verbal Comprehension and Naming Vocabulary. This cluster score reflects children's knowledge of verbal concepts, language comprehension and expression, level of vocabulary development, and general knowledge. Substantial evidence for construct validity, concurrent and criterion-related reliability for this cluster score exists (Elliot, 1990). Internal consistency for the preschool level is high (Cronbach's alpha $=.88$ ). Further, studies demonstrate a high correlation between DAS verbal ability and other well established indicators of intellectual ability (Elliot, 1990).

\subsection{Procedure}

Approval for the research activities was obtained from the University's Internal Review Board, the Director of the Head Start Program, and the Head Start Policy Council. Twelve classrooms were selected for participation, representing the program's six geographic clusters.

There were three types of data collection activities conducted early in the fall and late in the spring of the academic year (7 month interval). Data collected in the fall consisted of the ASPI completed by teachers as part of a program-wide assessment initiative to meet the federal Head Start Performance Standards. Additional data collected in the spring consisted of the following: (a) data from children's primary caregivers, (b) data from participating children's teachers, and (c) individual direct assessments of children. Prior to data collection, research team members met with parents (or primary caregiver) and teachers individually to explain the purpose of the study and to clarify issues of confidentiality, informed consent and data collection procedures. Ninety-five percent of the caregivers gave consent for their child to participate. This high rate of participation ensured that the study sample was representative of the Head Start program.

After obtaining parental consent for participation, research team members distributed questionnaire packets to parents that included a consent form and the PIPPS-P. All the teachers were asked to complete the ERC and a random subset were asked to complete the PLBS to reduce the workload. Teacher participation was $100 \%$. A team of graduate students with training in child development conducted individual direct assessments. The graduate students received extensive training in the DAS prior to its administration. Children were assessed individually outside of the Head Start classroom in a quiet place following a brief "warm-up" period. During the 15-20 min testing session, the two verbal subscales of the DAS were administered.

\subsection{Data analyses}

The first set of analyses was conducted to determine the relationship between the five dimensions of the ASPI assessed at the beginning of the year and the three social-emotional outcomes. First, bivariate correlations were attained between the fall ASPI dimensions and the ERC, PIPPS-P, and the PLBS. Then, hierarchical setwise multiple regression was used to examine the unique contribution of the ASPI to these outcomes, controlling for the influence of child demographic variables and verbal ability. Multivariate models were constructed for each set of social-emotional outcomes (i.e. dimensions of the ERC, PIPPS-P, and PLBS). Child demographic variables (age, gender) and the DAS Verbal Cluster Score were applied as 
control variables to account for variation in the criterion dimension by entering them first as two separate sets. The ASPI dimensions were entered as a final independent set to assess their unique contribution to the socio-emotional outcomes. The multivariate statistic, Wilks' Lambda $(\Lambda)$ was examined before inspecting the significance of the model for each dependent variable, and the incremental value of each set entered. The best model was evaluated in terms of: (a) the overall $R^{2}$ statistic, the proportion of variance in the criterion variable, explained by the best linear combination of the independent sets and (b) the partial $r^{2}$ statistic, which is the amount of variance uniquely associated with the last set entered, in this case, the set of ASPI dimensions. The sample size of 210 children provided adequate statistical power for these analyses, since a minimal sample of 107 is required to detect a medium effect with eight explanatory variables (with power set at .80 and alpha set at a .05 significance level) (Cohen, 1992).

\section{Results}

\subsection{Bivariate relationship between fall ASPI and spring outcomes}

The bivariate correlations between ASPI dimensions assessed in the fall and measures of emotion regulation, interactive peer play, and learning behaviors assessed in the spring are displayed in Table 1.

Table 1

Bivariate correlations of the fall ASPI with spring outcomes

\begin{tabular}{|c|c|c|c|c|c|}
\hline \multirow[t]{2}{*}{ Spring dimensions } & \multicolumn{5}{|l|}{ Fall ASPI } \\
\hline & Aggressive & $\begin{array}{l}\text { Inattentive/ } \\
\text { Hyperactive }\end{array}$ & Oppositional & $\begin{array}{l}\text { Withdrawn/ } \\
\text { Low Energy }\end{array}$ & $\begin{array}{l}\text { Socially } \\
\text { Reticent }\end{array}$ \\
\hline \multicolumn{6}{|l|}{ Classroom emotion regulation $^{\mathrm{a}}$} \\
\hline Lability/Negativity & $.38^{* * * *}$ & $.52^{* * * * *}$ & $.37^{* * * * *}$ & .07 & -.11 \\
\hline Emotion Regulation & -.10 & -.11 & $-.17^{*}$ & $-.35^{* * * *}$ & $-.29^{* * * *}$ \\
\hline \multicolumn{6}{|l|}{ Interactive peer play ${ }^{\mathrm{b}}$} \\
\hline Play Interaction & -.00 & -.10 & -.11 & $-.25^{* * *}$ & $-.20^{* *}$ \\
\hline Play Disruption & .06 & $.23^{* *}$ & $.19^{*}$ & -.01 & -.11 \\
\hline Play Disconnection & .12 & .13 & $.19^{*}$ & .08 & .04 \\
\hline \multicolumn{6}{|l|}{ Classroom learning behaviors ${ }^{\mathrm{c}}$} \\
\hline Competence Motivation & $-.37^{* * * *}$ & $-.43^{* * * *}$ & -.16 & $-.23^{* *}$ & -.03 \\
\hline Attention Persistence & $-.23^{* *}$ & $-.39^{* * * *}$ & -.13 & $-.22 *$ & -.04 \\
\hline Attitude Toward Learning & $-.31^{* * *}$ & $-.31^{* * * *}$ & -.12 & .01 & .14 \\
\hline \multicolumn{6}{|l|}{ Verbal ability $^{\mathrm{d}}$} \\
\hline DAS Verbal Cluster Score & -.05 & -.12 & .02 & $-.20^{* *}$ & -.05 \\
\hline
\end{tabular}

${ }^{\text {a }} N=200$.

${ }^{\mathrm{b}} N=170$.

c $N=126$.

d $N=210$.

${ }^{*} p<.05$.

** $p<.01$.

*** $p<.001$.

${ }^{* * * *} p<.0001$. 
A number of significant bivariate relationships emerged that provided additional convergent and divergent validity for the ASPI dimensions. ASPI underactive behavior problems (Withdrawn/Low Energy and Socially Reticent) were negatively associated with emotional competencies such as adaptive emotion regulation, interactive peer play in the home context, and motivated and attentive/persistent learning behaviors in the spring. ASPI overactive behavior problems (Aggressive, Inattentive/Hyperactive, and Oppositional) were positively correlated with labile emotion regulation and disruptive peer play in the spring. ASPI overactive problems were also negatively associated with learning behaviors.

\subsection{Relationship between the ASPI and emotion regulation}

Table 2 displays the results from the multivariate hierarchical setwise regression models indicating the amount of variation in classroom emotion regulation (ERC) explained by the set of ASPI dimensions [after accounting for variance associated with the covariates (child age, gender and verbal ability)]. The overall multivariate statistic, Wilks' Lambda was significant (Wilks' $\Lambda=.49, F[16,342]=.32, p<.0001$ ), permitting further inspection of the significance of each of the two dependent variable models (the ERC dimensions, Lability/Negativity, and Emotion Regulation). Both of the dimension models were

Table 2

Prediction of end-of-the-year emotion regulation by fall ASPI dimensions

\begin{tabular}{|c|c|c|}
\hline & \multicolumn{2}{|c|}{ Emotion regulation (ER-checklist) ${ }^{\mathrm{a}}$} \\
\hline & Lability/Negativity & Emotion Regulation \\
\hline \multicolumn{3}{|l|}{ Child demographic variables } \\
\hline Age & -.12 & .09 \\
\hline Gender & -.08 & $.15^{*}$ \\
\hline Verbal ability (DAS) & -.04 & .12 \\
\hline \multicolumn{3}{|l|}{ ASPI dimensions } \\
\hline Aggressive & .07 & -.13 \\
\hline Inattentive/Hyperactive & $.36^{* * * * *}$ & .07 \\
\hline Oppositional & $.29^{* * * *}$ & -.08 \\
\hline Withdrawn/Low Energy & .04 & $-.22^{* *}$ \\
\hline Socially Reticent & $-.18^{* *}$ & $-.20^{*}$ \\
\hline Variance explained by ASPI $^{\mathrm{b}}(\%)$ & $28.6^{* * * *}$ & $13.5^{* * * *}$ \\
\hline Variance explained by model ${ }^{\mathrm{c}}(\%)$ & $39.6^{* * * * *}$ & $19.0^{* * * * *}$ \\
\hline \multicolumn{3}{|l|}{$N=181$} \\
\hline \multicolumn{3}{|c|}{ ASPI dimensions. Values reflect the relative contribution of each dimension as covaried by child age, gender, and verbal ability. } \\
\hline \multirow{2}{*}{\multicolumn{3}{|c|}{$\begin{array}{l}\text { Tests assess the deviation of each parameter estimate from zero. } \\
\text { b Values equal the partial } r^{2}(100) \text { for prediction of ERC dimensions by all ASPI dimensions. All values are covaried for child } \\
\text { age, gender, and verbal ability. }\end{array}$}} \\
\hline & & \\
\hline \multicolumn{3}{|c|}{ c Values equal the multiple $R^{2}(100)$ for prediction of ERC dimensions for the entire model. } \\
\hline${ }^{*} p<.05$ & & \\
\hline \multicolumn{3}{|l|}{${ }^{* *} p<.01$} \\
\hline \multicolumn{3}{|l|}{${ }^{* * * *} p<.0001$} \\
\hline
\end{tabular}


significant, $F[8,172]=14.09, p<.0001$ for Lability/Negativity, and $F[8,172]=14.09, p<.0001$ for Emotion Regulation. The ASPI dimensions as a set accounted for a substantial amount of variance in the Lability/Negativity dimension $(28.6 \%)$ as indicated by the partial $r^{2}(F=.30, p<.0001)$ and in Emotion Regulation $(13.5 \%)$ as indicated by the partial $r^{2}(F=.73, p<.0001)$. Beta coefficients for each of the ASPI dimensions illustrate differential prediction patterns. ASPI inattentive/hyperactive and oppositional behaviors assessed at the beginning of the year were associated with higher lability/negativity at the end of the year $(\beta=36, p<.0001$ and $\beta=.29, p<.0001)$, and ASPI socially reticent behavior was associated with lower lability/negativity $(\beta=-.18, p<.01)$. The two underactive ASPI behavior problems assessed at the beginning of the year were associated with lower emotion regulation outcomes $(\beta=-.22, p<.01$ for Withdrawn/Low Energy and $\beta=-.20, p<.05$, for Socially Reticent dimensions).

\subsection{Relationship between the ASPI and interactive peer play}

Table 3 shows the amount of variation in interactive peer play (PIPPS-P) uniquely explained by the set of ASPI dimensions after applying covariates. The overall multivariate statistic, Wilks' Lambda was significant (Wilks' $\Lambda=.71, F[24,428.44]=2.29, p<.001$ ). Models for Play Disruption and Play Interaction were significant $(F[8,153]=2.32, p<.05$ and $F[8,153]=3.34, p<.01$, respectively $)$. ASPI dimensions as a set contributed a significant amount of variance to disruptive peer play behavior

Table 3

Prediction of end-of-the-year interactive peer play by fall ASPI dimensions

\begin{tabular}{lccc}
\hline & \multicolumn{2}{l}{ Interactive peer play (PIPPS-P) $^{\mathrm{a}}$} & \\
\cline { 2 - 4 } & Play Disconnection & Play Disruption & Play Interaction \\
\hline Child demographic variables & .10 & -.01 & $.22^{* *}$ \\
$\quad$ Age & -.01 & .03 & $.21^{*}$ \\
$\quad$ Gender & .06 & .04 & .15 \\
Verbal ability (DAS) & & & \\
ASPI dimensions & .03 & -.15 & -.02 \\
$\quad$ Aggressive & .08 & $.25^{*}$ & .11 \\
Inattentive/Hyperactive & .16 & $.20^{*}$ & -.08 \\
Oppositional & .09 & .03 & -.13 \\
$\quad$ Withdrawn/Low Energy & -.01 & $-.19^{*}$ & -.13 \\
$\quad$ Socially Reticent & 5.2 & $10.1^{* *}$ & 6.2 \\
Variance explained by ASPI & $(\%)$ & $10.8^{*}$ & $14.9^{* *}$ \\
Variance explained by model $l^{\mathrm{c}}(\%)$ & 5.8 & & \\
\hline
\end{tabular}

$N=162$.

${ }^{a}$ Entries are standardized parameter estimates $(\beta)$ derived in hierarchical multiple regression of the PIPP-P dimensions on the ASPI dimensions. Values reflect the relative contribution of each dimension as covaried by child age, gender, and verbal ability. Tests assess the deviation of each parameter estimate from zero.

${ }^{\mathrm{b}}$ Values equal the partial $r^{2}(100)$ for prediction of PIPPS-P dimensions by all ASPI dimensions. All values are covaried for child age, gender, and verbal ability.

${ }^{c}$ Values equal the multiple $R^{2}(100)$ for prediction of PIPPS-P dimensions for the entire model.

${ }^{*} p<.05$.

${ }^{* *} p<.01$. 
(10.1\%), partial $r^{2}=.10, p<.01$. Beta coefficients illustrate the following predictive patterns: inattentive/hyperactive and oppositional behaviors predicted higher disruptive peer play and withdrawn/low energy behaviors predicted lower disruptive play at the end of the year. In the prediction of interactive peer play behavior, the covariates, child age and gender, were the only significant contributors (partial $r^{2}=.059, F=5.23, p<.01$ ). (Older children and girls demonstrated higher interactive peer play outcomes.)

\subsection{Relationship between the ASPI and learning behaviors}

Table 4 displays the amount of variation in learning behaviors (PLBS) uniquely explained by the set of ASPI dimensions after applying covariates. The overall multivariate statistic, Wilks' Lambda was significant (Wilks' $\Lambda=.59, F[24,299.33]=2.50, p<.001$ ). Models for all criterion dimensions were significant, with $F[8,105]=3.92, p<.001$ for Competence Motivation, $F[8,105]=3.29, p<.01$ for Attention/Persistence, and $F[8,105]=3.09, p<.01$ for Attitude Toward Learning. ASPI dimensions contributed a significant amount of variance to Competence/Motivation (18.4\%) and Attitude Toward Learning $(11.5 \%)$ dimensions at the end of the year. The specific pattern of beta weights indicates that

Table 4

Prediction of end-of-the-year approaches learning behaviors by fall ASPI dimensions

\begin{tabular}{|c|c|c|c|}
\hline & \multicolumn{3}{|c|}{ Learning behaviors (PLBS) ${ }^{\mathrm{a}}$} \\
\hline & Competence Motivation & Attention/Persistence & Attitude Toward Learning \\
\hline \multicolumn{4}{|l|}{ Child demographic variables } \\
\hline Age & -.02 & .13 & -.05 \\
\hline Gender & .08 & .11 & .17 \\
\hline Verbal ability (DAS) & .06 & .17 & -.10 \\
\hline \multicolumn{4}{|l|}{ ASPI dimensions } \\
\hline Aggressive & $-.25^{*}$ & -.01 & $-.25^{*}$ \\
\hline Inattentive/Hyperactive & $-.23^{*}$ & $-.27^{*}$ & -15 \\
\hline Oppositional & -.01 & -.06 & .01 \\
\hline Withdrawn/Low Energy & -.16 & -.11 & -.03 \\
\hline Socially Reticent & -.01 & .01 & .06 \\
\hline Variance explained by ASPI ${ }^{\mathrm{b}}(\%)$ & $18.4^{* * *}$ & 8.6 & $11.5^{*}$ \\
\hline Variance explained by $\operatorname{model}^{\mathrm{c}}(\%)$ & $23.0^{* * * *}$ & $20.1^{* *}$ & $19.1^{* *}$ \\
\hline
\end{tabular}

$N=114$.

${ }^{\text {a }}$ Entries are standardized parameter estimates $(\beta)$ derived in hierarchical multiple regression of the PLBS dimensions on the ASPI dimensions. Values reflect the relative contribution of each dimension as covaried by child age, gender, and verbal ability. Tests assess the deviation of each parameter estimate from zero.

b Values equal the partial $r^{2}(100)$ for prediction of PLBS dimensions by all ASPI dimensions. All values are covaried for child age, gender, and verbal ability.

c Values equal the multiple $R^{2}(100)$ for prediction of PLBS dimensions for the entire model.

${ }^{*} p<.05$.

** $p<.01$.

*** $p<.001$. 
aggressive and inattentive behavior was associated with lower competence motivation and aggressive behavior was associated with lower attitude toward learning at the end of the year.

\section{Discussion}

The present study examined the unique relationship between multiple dimensions of classroom behavioral adjustment problems and salient social-emotional competencies for urban Head Start children. In accord with a developmental psychopathology model, maladaptation was conceptualized as persistent behavioral problems across diverse, routine classroom situations. It was hypothesize that socially negative, behavior problems and withdrawn classroom behavior, assessed early in the Head Start year, would be associated with later disruptions in children's ability to engage in positive peer play and instructional activities. These relationships are considered below for each distinct set of competencies investigated.

\subsection{Emotion regulation}

Socially negative behavior early in the school year, accounted for a significant amount of variance in emotion dysregulation at the end of the year. Children exhibiting early inattentive and oppositional behavior manifested greater levels of unpredictable and negative emotion in the classroom. Conversely, children demonstrating socially reticent behaviors displayed lower levels of this labile or negative emotionality. These findings are supported by literature suggesting an association between early externalizing problem behaviors and poor frustration tolerance, angry reactivity, affective intensity, and situationally inappropriate displays of negative emotions (Eisenberg, Fabes, Nyman, Bernzweig, \& Pinuelas, 1994; Shields \& Cicchetti, 1997). Further, research indicates that early inattentive or oppositional problems are directly related to emotional lability and difficulties with self-control (Bulotsky-Shearer \& Fantuzzo, 2004; Shields et al., 2001).

In addition, socially disconnected behavior in the classroom was associated with lower levels of adaptive emotional interactions and awareness of self and others. Children, who exhibited early withdrawn and socially reticent behavior, demonstrated less adaptive emotional regulation and affective engagement in the classroom at the end of the year. This replicates findings from previous research indicating that socially inhibited behavior problems are inversely related to adaptive self-regulation skills and engagement with peers (Bulotsky-Shearer \& Fantuzzo, 2004; Eisenberg, Shepard, Fabes, Murphy, \& Guthrie, 1998; Rubin, Cheah, \& Fox, 2001; Spinrad et al., 2004). Shields and Cicchetti (1997) suggest that withdrawn children may lack foundational skills such as flexibility, emotional understanding, and communication skills that underlie regulatory difficulties.

While the ASPI distinguishes between two types of underactive behavior, withdrawn/low energy and socially reticent behavior, in this study both types were related comparably to emotional regulation and interactive peer play outcomes. While very few studies make the distinction between two different underactive behaviors for preschool children, one recent study by Coplan, Prakash, O'Neil, and Arner (2004) identified two similar types of social withdrawal for preschool children using a parent-report measure. This research identified (a) conflicted shyness, defined by social fear and anxiety despite a desire to interact socially and reflected in reticent behavior and (b) social disinterest, defined by lack of a strong motivation to engage in social interaction. Indeed, this and other research suggests that both types are associated with difficulties in emotion regulation, interactive peer play and peer acceptance (Coplan et al., 2004; Hart et al., 2000). 


\subsection{Interactive peer play}

Preschool classroom behavioral adjustment problems uniquely contributed to children's interactive peer play competencies observed in the home and neighborhood context. Specifically, socially disruptive behavior (ASPI inattentive/hyperactive and oppositional behavior problems) predicted disruptive play outcomes in the home, while socially reticent behavior was inversely related to disruptive play. This finding is consistent with literature that links these classroom behavior problems to difficulties engaging in effective play with peers in both the school and home contexts. Studies with preschool children have demonstrated that conduct problems, aggressive and oppositional behavior, and hyperactivity in the classroom are associated with higher levels of disruptive play (Coolahan et al., 2000; Fantuzzo \& Bulotsky, 2003; Lutz et al., 2002). In a study of preschool classroom behavior and children's peer play in the home context, Fantuzzo and McWayne (2002) provide further evidence that conduct problems, hyperactivity, and inattention-passivity within the classroom are directly related to disruptive play in the home. Findings from the present study in concert with previous research, underscore that children exhibiting behavioral problems within the preschool classroom demonstrate greater difficulties interacting with peers across other contexts, such as the home and neighborhood context.

\subsection{Approaches to learning}

Children who exhibited socially and academically disruptive behavior (aggressive or inattentive classroom problems) early in the year demonstrated lower levels of cooperative, engaged, and attentive learning behaviors within the classroom. Specifically, aggressive behavior was associated with lower competence motivation and attitude toward learning - two dimensions that involve social transactions with learning (engagement with and responsiveness to teachers and peers). Children who displayed inattentive behaviors in the classroom also evidenced lower competence motivation and lower attention/persistence-skills that involve stability, focus, and attention to tasks within the learning context.

These findings are supported by previous research that has found inverse relationships between preschool classroom externalizing behavior and all three dimensions of approaches to learning (McDermott et al., 2002). Disruptive behavior in preschool also has been found to predict lower attention/persistence and attitude toward learning, while disconnected behavior predicted lower competence motivation (Fantuzzo et al., 2004). In addition, research with older children utilizing the Adjustment Scales for Children and Adolescents (ASCA) and the Learning Behaviors Scale (LBS), similarly found an inverse relationship between overactive classroom behavior (such as inattentive and oppositional behavior) and lower learning behavior competencies (McDermott, 1999). Further, in a factor analytic study of the LBS and ASCA, lower levels of inattentive, aggressive, and oppositional ASCA problem behavior were associated with higher attentive, persistent, strategic, and flexible learning behaviors. Avoidant and diffident problem behaviors were associated with lower competence motivation and attitude toward learning (McDermott, Mordell, \& Stoltzfus, 2001).

\subsection{Directions for future research}

The present study extends research on early classroom behavioral adjustment problems for low-income, urban children in four distinct ways. First, the study employed a developmentally appropriate and ecologically sensitive assessment of children's difficulties adapting to the demands of multiple preschool 
classroom situations. Second, this study utilized a hierarchical model that accounted for the variance associated with child age, gender, and verbal ability, to determine the unique contribution of early classroom behavioral adjustment problems to a comprehensive set of children's social-emotional outcomes. Third, this study used a relevant set of social-emotional outcomes assessed at the end of the preschool year. These social-emotional competencies included self-regulation skills evidenced at school, interactive peer play behaviors exhibited in the home, and approaches to learning as observed by the teacher. The inclusion of this last competency adds to the sparse literature on the relationship between preschool behavior problems and children's approaches to learning (NEGP, 1997). Finally, this study further contributes to previous research by investigating the impact of preschool behavior problems on social-emotional competencies assessed across both primary contexts of home and school.

As a relatively large-scale investigation of these relationships with urban Head Start children, the present study had two primary limitations - the characteristics of the sample and the source of measurement for two of the social/emotional variables. As such, this study primarily investigated low-income, urban, African-American children in Head Start. The application of these findings to other populations of low-income, preschool children is qualified. Next steps should determine whether the relation ships reported here between early classroom behavior problems and later social/emotional outcomes generalize to other groups of vulnerable children who are linguistically, ethnically, and regionally different from the present sample. Furthermore, future studies would be enhanced by collecting key family variables, such as single-parenthood, maternal education, and maternal depression, which have been associated with increased risk of children's later emotional and behavioral difficulty (Raver, 2002; Raver \& Knitzer, 2002).

The findings in the present study regarding the relationships between early multidimensional assessments of classroom adjustment problems and later assessments of emotional regulation and approaches to learning were qualified by the use of a single source of assessment - the teacher. The use of teacher rating scales for these constructs may have contributed to shared method and source variance. There is a risk that teachers if asked to rate a child's classroom performance early in the school year may hold on to their judgment at a later point in the year (McNeilly-Choque, Hart, Robinson, Nelson, \& Olsen, 1996). However, the use of teacher report measures in this study must be seen within the larger context of the preschool assessment literature. This literature is characterized by both a lack of psychometrically sound options for assessing culturally and linguistically diverse preschool children (Lopez et al., 2000), and a substantiated rationale for using credentialed teachers as a primary source of data on classroom functioning. Teacher rating scales, particularly the ones used in this study, are the only available measures of these classroom-based constructs for this population that can be practically administered on a large scale. Furthermore, teachers are relatively accurate, reliable, and unobtrusive observers of classroom phenomena (McNeilly-Choque et al., 1996; Schuck, Oehler-Stinnett, \& Stinnett, 1995). Because of their familiarity with many different children over time and their exposure to infrequently occurring, but significant behavior, they are natural and valuable informants for classroom behaviors (McNeilly-Choque et al., 1996). The measures that were used in this study called for teachers to identify/rate observable behaviors in different classroom situations (e.g., in learning activities, free play, and general classroom activities). This increases the likelihood that the observed overlap in teachers' responses on these measures is attributable to consistencies in child behavior across contexts, rather than to teachers rating the same behaviors on different measures or basing their responses across measures on a single observation or impression of the child. Nonetheless, future smaller scale studies could test the present findings using independent observers and assessors to evaluate children's social/emotional outcomes. Incorporating 
outcomes measures from additional sources will enhance our understanding of the relationships under study.

Further investigations are needed to examine classroom quality and teacher characteristics (e.g., years of experience, ethnicity, level of training) in relation to children's classroom behavioral adjustment. Several studies demonstrate strong associations between quality early childhood educational experiences and positive school outcomes (Campbell, Pungello, Miller-Johnson, Burchinal, \& Ramey, 2001). Factors such as teacher-to-child ratio, teacher training, and close teacher-student relationships in preschool classrooms have been linked to better social, emotional, and cognitive outcomes (Burchinal, Peisner-Feinberg, Bryant, \& Clifford, 2000; Howes, Phillipsen, \& Peisner-Feinberg, 2000). Studies that employ hierarchical, ecological models and include information regarding this important context may serve to illuminate factors, which ameliorate or exacerbate children's classroom behavioral adjustment adjustment problems and later outcomes (Raver, 2002).

\subsection{Implications for policy and practice}

There are a number of important implications of this research. This study extends our understanding of classroom behavioral adjustment problems by capturing children's difficulties within the context of natural, routine preschool situations by key contributors to children's development-teachers and parents (Fantuzzo, McWayne, \& Bulotsky, 2003). This more developmentally and ecologically appropriate method provides a richer and more accurate assessment of children's behavior than traditionally used psychopathology checklists. Information from this assessment approach, allows teachers and teacher assistants to identify children's behavior across multiple classroom situations early in the school year. The teaching team can target relevant situations, creating classroom interventions that may alter problem behavior across the school year. These interventions can increase access to appropriate services for children within the natural setting of the preschool classroom (Fantuzzo, McWayne, \& Bulotsky, 2003). Moreover, by identifying difficulties that are common across classrooms, exemplary teachers can share classroom management and intervention strategies. This dialogue can enhance support amongst teachers, professional staff, and mental health consultants (Raver \& Knitzer, 2002).

Through its extension to incorporate the home context, this study recognized parents' voices in the assessment process. Including parent as well as teacher feedback regarding the contribution of children's classroom behavioral adjustment problems to end-of-the-year competencies across home and school provided an enhanced picture of children's trajectories. Policies should be implemented to more overtly and meaningfully include parents in the assessment process to create continuity of involvement, more genuine connection between home and school, and to foster dialogue regarding early intervention for children exhibiting difficulties. Because early classroom behavioral adjustment problems are shaped by factors in both home and school environments, these contexts should be incorporated into interventions for preschool children (McEvoy \& Welker, 2000). The Head Start program represents a strategic place to develop and test comprehensive interventions because of its explicit two-generation focus, whole-child perspective, and commitment to professional development of teachers.

The present study underscores the importance of early identification for low-income, urban Head Start children. These findings provide evidence to further dispel the myth that "children will grow out of" these problems (Knitzer, 2003). According to the results of this study, problems persist across time, suggesting that children with early adaptation difficulties are at higher risk for continued difficulties without timely identification and intervention. The use of ecologically sensitive, multidimensional scales, like the ASPI, 
provides ways to examine distinctive classroom behavioral adjustment patterns that can inform intervention within the natural preschool classroom context. Information from such scales can also be used to stimulate educational dialogue regarding appropriate teacher responses to different patterns of behavioral difficulties, the differential effectiveness of interventions for both overactive (socially disruptive) and underactive (disengaged) behavior problems, and the dynamic collaboration between home and school.

\section{References}

Brooks-Gunn, J., \& Duncan, G. J. (1997). The effects of poverty on children. Future of Children, 7(2), 55-71.

Bulotsky-Shearer, R., \& Fantuzzo, J. (2004). Adjustment scales for preschool intervention: Extending validity and relevance across multiple perspectives. Psychology in the Schools, 41, 725-736.

Burchinal, M. R., Peisner-Feinberg, E. S., Bryant, D. M., \& Clifford, R. M. (2000). Children's social and cognitive development and child care quality: Testing for differential associations related to poverty, gender, or ethnicity. Applied Developmental Science, 4, 149-165.

Campbell, F. A., Pungello, E. P., Miller-Johnson, S., Burchinal, M., \& Ramey, C. T. (2001). The development of cognitive and academic abilities: Growth curves from an early childhood educational experiment. Developmental Psychology, 37(2), 231-242.

Cicchetti, D., \& Sroufe, L. A. (2000). The past as prologue to the future: The times, they've been a-changin'. Development \& Psychopathology. Special Issue: Reflecting on the Past and Planning for the Future of Developmental Psychopathology, 12(3), 255-264.

Cohen, J. (1992). A power primer. Psychological Bulletin, 112(1), 155-159.

Coolahan, K., Fantuzzo, J., Mendez, J., \& McDermott, P. (2000). Preschool peer interactions and readiness to learn: Relationships between classroom peer play and learning behaviors and conduct. Journal of Educational Psychology, 92(3), 458465.

Coplan, R. J., Prakash, K., O’Neil, K., \& Armer, M. (2004). Do you “want” to play? Distinguishing between conflicted shyness and social disinterest in early childhood. Developmental Psychology, 40(2), 244-258.

Denham, S. A. (1998). Emotional development in young children. New York: Guilford Press.

Denham, S. A., Blair, K. A., DeMulder, E., Levitas, J., Sawyer, K., Auerbach-Major, S., et al. (2003). Preschool emotional competence: Pathway to social competence. Child Development, 74(1), 238-256.

Denham, S. A., Salisch, M., Olthof, T., Kochanoff, A., \& Caverly, S. (2002). Emotional and social development in childhood. In P. K. Smith \& C. H. Hart (Eds.), Blackwell handbook of childhood social development (pp. 307-328). Oxford, England: Blackwell Publishers.

Drotar, D., Stein, R. E. K., \& Perrin, E. C. (1995). Methodological issues in using the Child Behavior Checklist and its related instruments in clinical child psychology research. Journal of Clinical Child Psychology. Special Issue: Methodological Issues in Clinical child Psychology Research, 24(2), 184-192.

Eisenberg, N., Cumberland, A., Spinrad, T. L., Fabes, R. A., Shepard, S. A., Reiser, M., et al. (2001). The relations of regulation and emotionality to children's externalizing and internalizing problem behavior. Child Development, 72(4), 11121134.

Eisenberg, N., \& Fabes, R. A. (1992). Emotion, regulation, and the development of social competence. In M. S. Clark (Ed.), Emotion and social behavior. Review of personality and social psychology (Vol. 14, pp. 119-150). Thousand Oaks, CA: Sage Publications, Inc.

Eisenberg, N., Fabes, R. A., Nyman, M., Bernzweig, J., \& Pinuelas, A. (1994). The relations of emotionality and regulation to children's anger-related reactions. Child Development, 65(1), 109-128.

Eisenberg, N., Shepard, S., Fabes, R., Murphy, B., \& Guthrie, I. (1998). Shyness and children's emotionality, regulation, and coping: Contemporaneous, longitudinal, and across-context relations. Child Development, 69, 767-790.

Elliot, C. D. (1990). Differential ability scales: Adminstration and scoring manual. San Antonio, TX: The Psychological Corporation.

Fantuzzo, J. W., Bulotsky, R., McDermott, P., Mosca, S., \& Lutz, M. N. (2003). A multivariate analysis of emotional and behavioral adjustment and preschool educational outcomes. School Psychology Review, 32(2), 185-203. 
Fantuzzo, J. W., Grim, S., Mordell, M., McDermott, P., Miller, L., \& Coolahan, K. (2001). A multivariate analysis of the revised Conners' Teacher Rating Scale with low-income, urban preschool children. Journal of Abnormal Child Psychology, 29(2), $141-152$.

Fantuzzo, J. W., \& Hampton, V. R. (2000). Penn Interactive Peer Play Scale: A parent and teacher rating system for young children. In K. Gitlin-Weiner \& A. Sandgrund (Eds.), Play diagnosis and assessment (2nd ed., pp. 599-620). New York, NY: John Wiley \& Sons, Inc.

Fantuzzo, J. W., \& McWayne, C. (2002). The relationship between peer-play interactions in the family context and dimensions of school readiness for low-income preschool children. Journal of Educational Psychology, 94(1), 7987.

Fantuzzo, J. W., McWayne, C., \& Bulotsky, R. (2003). Forging strategic partnerships to advance mental health science and practice for vulnerable children. School Psychology Review, 32(1), 17-37.

Fantuzzo, J. W., Mendez, J. L., \& Tighe, E. (1998). Parental assessment of peer play: Development and validation of the parent version of the Penn Interactive Peer Play Scale. Early Childhood Research Quarterly, 13, 655-672.

Fantuzzo, J. W., \& Mohr, W. K. (2000). Pursuit of wellness in Head Start: Making beneficial connections for children and families. In D. Cicchetti \& J. Rappaport (Eds.), The promotion of wellness in children and adolescents (pp. 341-369). Washington, DC: Child Welfare League of America, Inc.

Fantuzzo, J. W., Perry, M. A., \& McDermott, P. (2004). Preschool approaches to learning and their relationship to other relevant classroom competencies for low-income children. School Psychology Quarterly, 19, 212-230.

Harden, B. J., Winslow, M. B., Kendziora, K. T., Shahinfar, A., Rubin, K. H., Fox, N. A., et al. (2000). Externalizing problems in Head Start children: An ecological exploration. Early Education \& Development. Special Issue: Mental Health and Head Start, 11(3), 357-385.

Hart, C. H., Yang, C., Nelson, L. J., Robinson, C. C., Olsen, J. A., Nelson, D. A., et al. (2000). Peer acceptance in early childhood and subtypes of socially withdrawn behavior in China, Russia, and the United States. International Journal of Behavioral Development, 24, 73-81.

Howes, C., Phillipsen, L. C., \& Peisner-Feinberg, E. (2000). The consistency of perceived teacher-child relationships between preschool and kindergarten. Journal of School Psychology, 38, 113-132.

Huffman, L. C., Mehlinger, S. L., \& Kerivan, A. S. (2000). Risk factors for academic and behavioral problems at the beginning of school. In Off to a good start: Research on the risk factors for early school problems and selected federal policies affecting children's social and emotional development and their readiness for school. Chapel Hill: University of North Carolina, Frank Porter Graham Child Development Center.

Kaiser, A. P., Cai, X., Hancock, T. B., \& Foster, E. M. (2002). Teacher-reported behavior problems and language delays in boys and girls enrolled in Head Start. Behavioral Disorders, 28(1), 23-39.

Knitzer, J. (January 2003). Social and emotional development in young low-income children: What research tells us and why it matters for early school success. In Paper presented at the testimony presented at the head start hearing.

Lavigne, J. V., Gibbons, R. D., Christoffel, K. K., Arend, R., Rosenbaum, D., Binns, H., et al. (1996). Prevalence rates and correlates of psychiatric disorders among preschool children. Journal of the American Academy of Child \& Adolescent Psychiatry, 35(2), 204-214.

Lopez, M. L., Tarullo, L. B., Forness, S. R., \& Boyce, C. A. (2000). Early identification and intervention: Head Start's response to mental health challenges. Early Education \& Development, 11(3), 265-282.

Lutz, M. N., Fantuzzo, J., \& McDermott, P. (2002). Multidimensional assessment of emotional and behavioral adjustment problems of low-income preschool children: Development and initial validation. Early Childhood Research Quarterly, 17(3), 338-355.

Mallory, B. L., \& Kearns, G. M. (1998). Consequences of categorical labeling of preschool children. Topics in Early Childhood Special Education, 8, 39-50.

McDermott, P. A. (1993). National standardization of uniform multisituational measures of child and adolescent behavior pathology. Psychological Assessment, 5(4), 413-424.

McDermott, P. A. (1999). National scales of differential learning behaviors among American children and adolescents. School Psychology Review, 28(2), 280-291.

McDermott, P., Bulotsky-Shearer, R., \& Fantuzzo, J. (2003). Adjustment scale for preschool intervention manual. Philadelphia: Edumetric and Clinical Science.

McDermott, P. A., Green, L. F., Francis, J. M., \& Stott, D. H. (1996). Preschool learning behaviors scale. Philadelphia: Edumetric and Clinical Science. 
McDermott, P. A., Leigh, N. M., \& Perry, M. A. (2002). Development and validation of the Preschool Learning Behaviors Scale. Psychology in the Schools, 39(4).

McDermott, P. A., Mordell, M., \& Stoltzfus, J. C. (2001). The organization of student performance in American schools: Discipline, motivation, verbal learning, nonverbal learning. Journal of Educational Psychology, 93(1), 65-76.

McEvoy, A., \& Welker, R. (2000). Antisocial behavior, academic failure, and school climate: A critical review. Journal of Emotional and Behavioral Disorders, 8, 130-140.

McLoyd, V. C. (1998). Socioeconomic disadvantage and child development. American Psychologist, 53(2), 185-204.

McNeilly-Choque, M., Hart, C., Robinson, C., Nelson, L., \& Olsen, S. (1996). Overt and relational aggression on the playground: Correspondence among different informants. Journal of Research in Childhood Education, 31, 47-67.

NEGP. (1997). Getting a good start in school. Washington, DC: National Education Goals Panel.

Olson, S. L., \& Hoza, B. (1993). Preschool developmental antecedents of conduct problems in children beginning school. Journal of Clinical Child Psychology, 22(1), 60-67.

Qi, C. H., \& Kaiser, A. P. (2003). Behavior problems of preschool children from low-income families: Review of the literature. Topics in Early Childhood Special Education, 23(4), 188-216.

Raver, C. C. (2002). Emotions matter: Making the case for the role of young children's emotional development for early school readiness. Social Policy Report, 16(3), 3-19.

Raver, C. C., \& Knitzer, J. (2002). Ready to enter: What research tells policymakers about strategies to promote social and emotional school readiness among three- and four-year-old children. New York: National Center for Children in Poverty, Mailman School of Public Health, Columbia University.

Rubin, K. H., Cheah, C. S. L., \& Fox, N. (2001). Emotion regulation, parenting and display of social reticence in preschoolers. Early Education \& Development, 12(1), 97-115.

Rubin, K. H., \& Coplan, R. J. (1998). Social and nonsocial play in childhood: An individual differences perspective. In O. N. Saracho \& B. Spodek (Eds.), Multiple perspectives on play in early childhood education. SUNY series, early childhood education: Inquiries and insights (pp. 144-170). Albany, NY: State University of New York Press.

Schuck, L. A., Oehler-Stinnett, J., \& Stinnett, T. A. (1995). Predictive validity of the Teacher Rating of Academic Achievement Motivation (TRAAM) with Hispanic students. Journal of Psychoeducational Assessment, 13, 143-156.

Sherrod, L. R. (1999). A commentary on "Head Start and mental health: An argument for early screening and intervention" by Edward G. Feil. National Head Start Association Dialog, 2, 412-415.

Shields, A., \& Cicchetti, D. (1995). The development of an emotion regulation assessment battery: Reliability and validity among at-risk grade-school children. In Paper presented at the Society for Research in Child Development.

Shields, A., \& Cicchetti, D. (1997). Emotion regulation among school-age children: The development and validation of a new criterion Q-sort scale. Developmental Psychology, 33, 906-916.

Shields, A., Dickstein, S., Seifer, R., Giusti, L., Magee, K. D., \& Spritz, B. (2001). Emotional competence and early school adjustment: A study of preschoolers at risk. Early Education \& Development, 12(1), 73-96.

Shonkoff, J. P., \& Phillips, D. (Eds.). (2000). From neurons to neighborhoods: The science of early childhood development. Washington, DC: National Academy Press.

Sinclair, E., Del'Homme, M., \& Gonzalez, M. (1993). Systematic screening for preschool behavioral disorders. Behavioral Disorders, 18(3), 177-188.

Spinrad, T. L., Eisenberg, N., Harris, E., Hanish, L., Fabes, R. A., Kupanoff, K., et al. (2004). The relation of children's everyday nonsocial peer play behavior to their emotionality, regulation, and social functioning. Developmental Psychology, 40(1), $67-80$.

U.S. Department of Education (1996). Urban schools: The challenge of location and poverty.

U.S. Department of Health and Human Services. (2001). Report of the surgeon general's conference on children's mental health: A national action agenda. Washington, DC: U.S. Department of Health and Human Services.

Vaughn, S., Hogan, A., Lancelotta, G., Shapiro, S., et al. (1992). Subgroups of children with severe and mild behavior problems: Social competence and reading achievement. Journal of Clinical Child Psychology, 21(2), 98-106. 